\title{
Alternative Indexes to Estimate the Functional Capacity From the 6-Minute Walk Test in Children and Adolescents With Cystic Fibrosis
}

\author{
Renata Tiemi Okuro PhD, Maria Angela Gonçalves de Oliveira Ribeiro PhD, \\ José Dirceu Ribeiro PhD, Rafaela Coelho Minsky MSc, and Camila Isabel Santos Schivinski PhD
}

\begin{abstract}
BACKGROUND: Cystic fibrosis is a multi-systemic disease related to reduced functional capacity. The distance covered in the 6-min walk test (6MWT) has been known to assess functional capacity, but little is known about other indexes that can be derived. We sought to compare the performance during the 6MWT and the estimated indexes of functional capacity from the 6MWT between subjects with cystic fibrosis (CF) and healthy individuals as well as to assess the relationship among these indexes and disease severity, pulmonary function, and nutritional status in CF. METHODS: This cross-sectional study was carried out at a university referral center for $\mathrm{CF}$. It included a group of 55 non-oxygen-dependent CF subjects (CF group) with no acute pulmonary exacerbations and a group of 185 healthy controls (control group). All subjects were submitted to 6MWT and anthropometrics measurements. RESULTS: Regarding performance during the 6MWT, the mean values of work, physiological cost index, average velocity, and 6-min walk distance (6MWD) were significantly lower in the $\mathrm{CF}$ group than in the control group (work: $21,690.58 \pm 10,427.77$ vs $26,057.51 \pm 11,228.49 \mathrm{~m} \times \mathrm{kg}[P=.007]$; physiological cost index: $0.31 \pm 0.19$ vs $0.37 \pm 0.17$; average velocity: $94.71 \pm 12.89$ vs $104.55 \pm 9.13 \mathrm{~m} / \mathrm{min}[P<.001]$; and $6 \mathrm{MWD}: 568.02 \pm 76.31 \mathrm{~m}$ versus $627.54 \pm 54.81 \mathrm{~m}[P<.001])$. Subjects with less severe CF had higher 6MWD, work, and average velocity during the 6MWT, compared with subjects with more severe $\mathrm{CF}(P=.008, P=$ .01 , and $P=.007$, respectively). There was a correlation between $6 \mathrm{MWD}$, work, average velocity, and disease severity and pulmonary function. CONCLUSIONS: Considering the importance of standard measure (6MWD) the in 6MWT, alternative indexes can be useful as complementary outcomes and to provide a better understanding of limiting factors of exercise response in children and adolescents with CF. Key words: cystic fibrosis; exercise test; exercise tolerance; exercise. [Respir Care 2017;62(3):324-332. (C) 2017 Daedalus Enterprises]
\end{abstract}

\section{Introduction}

Cystic fibrosis $(\mathrm{CF})$ is a multi-systemic genetic disease, which follows an autosomal recessive pattern of inheri-

\footnotetext{
Dr Okuro is affiliated with the Faculty of Medical Sciences, State University of Campinas (UNICAMP), Brazil. Dr Oliveira Ribeiro is affiliated with UNICAMP and the Pulmonary Function Laboratory (LAFIP) at CIPED (Center for Investigation in Pediatrics), Department of Pediatrics, Faculty of Medical Sciences (FCM)/UNICAMP, Brazil. Dr Ribeiro is affiliated with the Department of Pediatrics at the Faculty of Medical Sciences, UNICAMP, SP, Brazil and LAFIP of CIPED, FCM/UNICAMP. Ms Minsky is affiliated with the State University of Santa Catarina (UDESC), Brazil. Dr Schivinski is affiliated with UDESC and UNICAMP, Brazil.
}

tance. Its clinical manifestations and severity of symptoms may vary considerably from one patient to another. ${ }^{1}$

The disease mainly affects the respiratory and digestive tracts. Thus, there are both deterioration in nutritional status and irreversible loss of lung function, which cause individual severe physical limitations and are directly related to reduced functional capacity. ${ }^{2}$

\footnotetext{
Correspondence: Camila Isabel Santos Schivinski PhD, Rua Pascoal Simone, 358, Coqueiros-Florianópolis-SC, CEP: 88080-350, Brazil. E-mail: cacaiss@yahoo.com.br.
}

DOI: $10.4187 /$ respcare. 04625 
Higher levels of aerobic fitness are associated with improved survival. ${ }^{3,4}$ Therefore, valid and reliable tests to assess cardiorespiratory response are of the utmost importance. They will help to determine the functional status, evolution, and prognosis of patients with $\mathrm{CF}$ as well as providing guidance for prescribing individualized physical activity programs. ${ }^{5}$

The 6-min walk test (6MWT) assesses responses to submaximal exercise. It has been increasingly used in clinical trials, mainly in cases of cardiopulmonary conditions, such as CF, where the patient's exercise capacity and physical activity level can be limited. ${ }^{6}$ It is indicated for functional capacity evaluations, epidemiologic research, monitoring of effectiveness of interventions, and prognosis by predicting morbidity and mortality. ${ }^{7}$ The $6 \mathrm{MWT}$ is also considered an inexpensive tool as well as an easily reproducible test in outpatient settings with good measures of reliability and of great importance in clinical practice. ${ }^{8}$

Furthermore, the 6MWT is well-recognized and commonly used in clinical and functional monitoring of patients with CF. The 6MWT follows up on the development of the disease and does not require either expensive equipment or a trained multidisciplinary team. ${ }^{9}$

The 6-min distance walked (6MWD) has routinely been used to assess submaximal functional capacity in adults. ${ }^{6,8}$ However, interpretation of results of 6MWTs conducted in the pediatric population has proved to be more difficult. Major reasons include great variability of anthropometric characteristics of the population, lack of reference values for this age group, and lack of a specific minimum difference of $6 \mathrm{MWD}$, which enables the prediction of clinical improvement after different interventions and provides limited interpretation of test results.

Therefore, alternative indexes have been proposed to assess physical performance (ie, 6-min walk work, ${ }^{10,11}$ average velocity during the test, ${ }^{12}$ and physiological cost index). ${ }^{13-15}$ They were created to assess exercise response, considering other determining factors involved in exercise tolerance and elements that affect it. These indexes can be easily obtained from variables of the 6MWT and provide additional information on exercise tolerance assessment of patients with $\mathrm{CF}$, mainly in the pediatric population.

In this context, the objective of this study was to compare the 6MWD between subjects with CF and healthy individuals, considering the estimated indexes of functional capacity from the 6MWT (work, average velocity, and physiological cost index). Furthermore, it aimed to assess the relationship of these variables with disease severity, pulmonary function, and nutritional status in children and adolescents with CF.

\section{QUICK LOOK}

\section{Current knowledge}

The distance covered during the 6-min walk test (6MWT) has been routinely used to assess submaximal functional capacity. In pediatric patients with cystic fibrosis, however, the interpretation of this measure is limited, mainly by the variability of anthropometric outcomes and lack of references values. Alternative indexes easily estimated from 6MWT variables have been proposed to assess other determining factors involved in exercise tolerance and elements that affect it.

\section{What this paper contributes to our knowledge}

Alternative indexes of functional capacity obtained by $6 \mathrm{MWT}$ were useful as complementary parameters to provide a better understanding of limiting factors of exercise response in children and adolescents with cystic fibrosis.

\section{Methods}

This cross-sectional study was carried out with a group of subjects with CF (the CF group) regularly monitored in the $\mathrm{CF}$ out-patient unit at a university referral hospital from March 2009 to March 2011.

The project was approved by the research ethics committee of the Faculty of Medical Sciences (FCM/UNICAMP), under protocol number 504/2008. Before starting the study, all participants $\geq 18$ y old were informed of the study and signed an informed consent document. For subjects $<18$ y old, the informed consent document was signed by the minor's parent or guardian.

Subjects age 6-18 y with a confirmed diagnosis of CF by compatible clinical manifestation and 2 altered sweat tests (sweat chloride concentration $>60 \mathrm{mEq} / \mathrm{L}$ ) and/or the presence of 2 cystic fibrosis transmembrane regulator gene mutations were included in the study. Individuals with acute pulmonary exacerbations according to the cystic fibrosis clinical score $(\geq 25)^{16}$ and the cystic fibrosis foundation score $(\geq 4)^{17}$ and patients receiving long-term oxygen therapy were excluded from the study. All children and adolescents between 6 and 18 y old treated in the out-patient clinic at the hospital were invited to participate in the study. Data were collected before the routine appointments.

The control group included students from public and private elementary schools and volunteers between 6 and 18 y old, non-smokers, non-athletes without a previous history of respiratory diseases, and individuals with orthopedic impairments. 

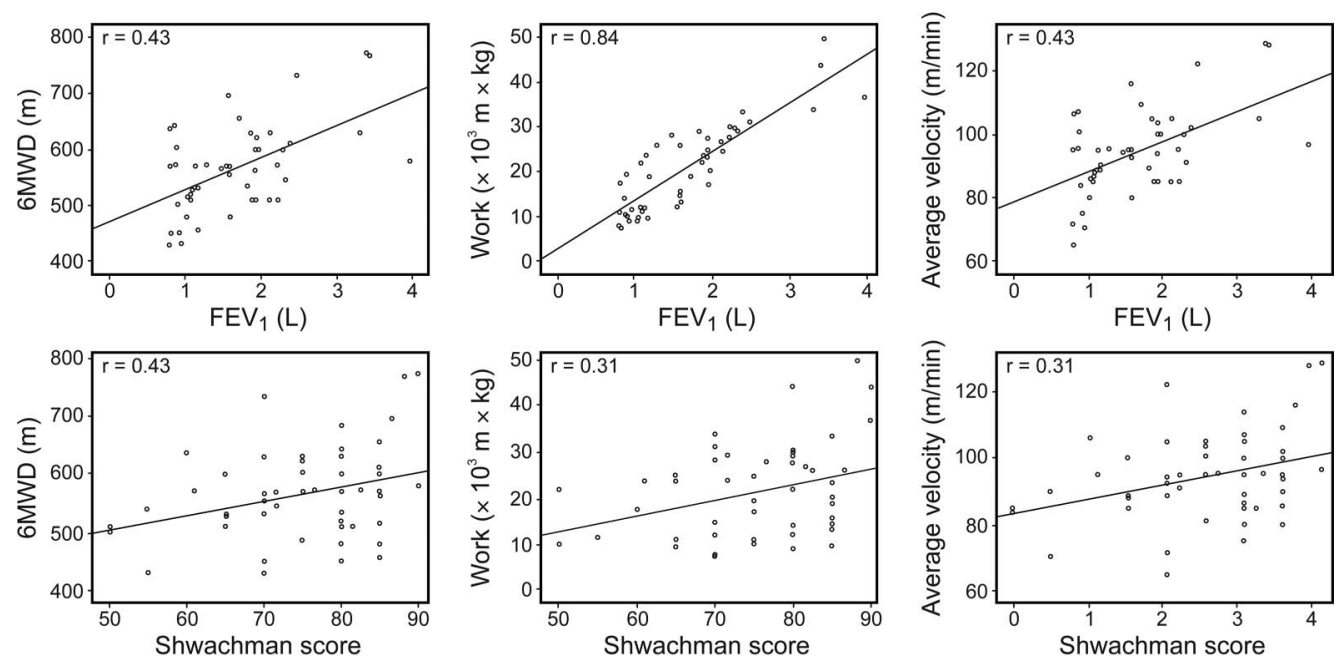

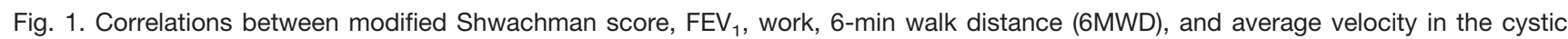
fibrosis group.

First, anthropometric measurements (weight and height) were taken, and the body mass index (BMI) was calculated according to the standards of the Center for Disease Control, considering sex and age (BMI for age percentiles for boys and girls). A stadiometer was used for measuring height. Anthropometric measures were taken, and the modified Shwachman scoring system ${ }^{18,19}$ was also applied to the CF group. ${ }^{20}$ The modified Shwachman scoring system evaluated general activity, physical examination, nutrition, and radiological findings, with a range from 20 to 100 points. The subjects were divided into the following groups: severe (score $<40)$, moderate $(40-55)$, average $(56-70)$, good (71-85), and excellent (86-100). Then the 6MWT was performed in compliance with the recommendations of the American Thoracic Society. ${ }^{8}$ During the test, the following items were assessed: heart rate, breathing frequency, oxygen saturation (using a portable pulse oximeter [Oximed Plus, Oximed, Porto Alegre, Brazil]), and the subjective sensation of dyspnea by the Borg scale. ${ }^{8}$ All participants repeated the $6 \mathrm{MWT}$ after $30 \mathrm{~min}$ of rest. The 6MWD of both groups was compared with age-predicted values, according to Priesnitz et al ${ }^{21}$ (Fig. 1).

The functional performance variables were obtained from the 6MWD. The 6-min walk work was calculated using the equation, work $=6 \mathrm{MWD}(\mathrm{m}) \times$ body weight $(\mathrm{kg}){ }^{10,11}$ Average velocity $(\mathrm{m} / \mathrm{min})$ was equal to 6MWD divided by the test duration $(6 \mathrm{~min}) .^{12}$ The physiological cost index was calculated by the difference between resting heart rate value and heart rate at the end of the test, divided by average velocity $(\mathrm{m} / \mathrm{min})$, and expressed as heart $\mathrm{rate} / \mathrm{m} / \mathrm{min}$ (physiological cost index $=$ final heart rate - initial heart rate/average velocity). ${ }^{13-15}$ The sample selection and how the data collection was done are summarized in Figure 2.
The most recent spirometry test performed in the last 3 months before the completion of the 6MWT was assessed to characterize lung function in the CF group. The $\mathrm{FEV}_{1}$ was expressed as the percentage of the predicted value. ${ }^{22}$ The subjects were grouped according to the percentage of the predicted value into 4 subgroups, namely $>80 \%$ of predicted value, $60-80 \%, 40-59 \%$, and $<40 \%$. All spirometry tests were performed at the Pulmonary Function Laboratory of the Faculty of Medical Science (State University of Campinas, Campinas, Brazil), using a CPFS/D spirometer (Medical Graphics, Saint Paul, Minnesota) and following American Thoracic Society norms. ${ }^{23}$ Information about the presence of gene mutations and history of pancreatic insufficiency was collected from all subjects.

The sample size was planned, considering all eligible patients of a $\mathrm{CF}$ reference center to accommodate a ratio of at least 2 controls per CF subject. SPSS 16.0 (SPSS, Chicago, Illinois) was used for the analysis of the data. First, the Kolmorov-Smirnov and Shapiro-Wilk tests were applied to check whether the data were normally distributed as well as to assess symmetry, kurtosis, and data distribution by histogram. Next, the Mann-Whitney test was used to compare the performance of alternative indexes of the 6MWT between the CF group and the control group and to compare the 6MWD of each group in relation to age-predicted values. The Kruskal-Wallis test was used to analyze the CF group behavior according to the alternative indexes of disease severity and FEV ${ }_{1}$. The Spearman test was used to investigate correlations between the variables of $6 \mathrm{MWD}$, work, average velocity, physiological cost index, BMI, and scores of the modified Shwachman scoring system and $\mathrm{FEV}_{1}$ in the $\mathrm{CF}$ group. The significance level considered was $5 \%$ for all tests. 


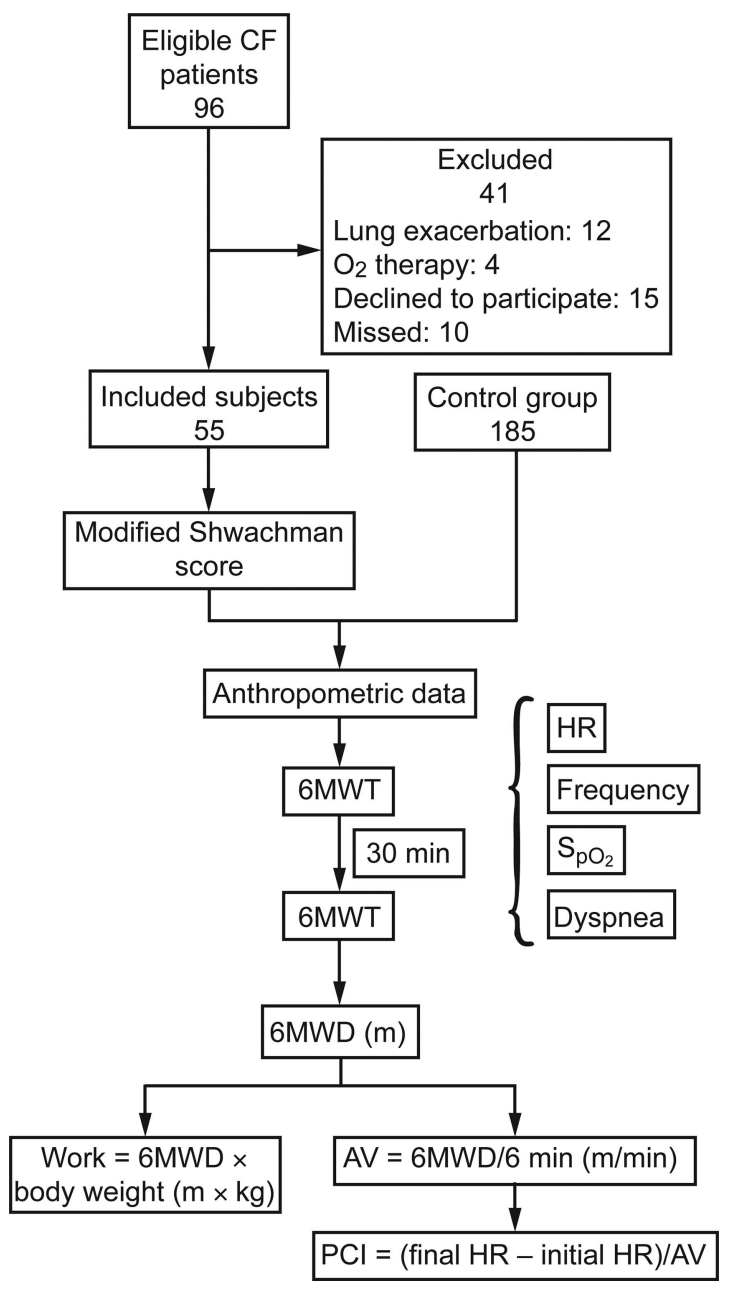

Fig. 2. Flow chart and data collection. $6 \mathrm{MWT}=6$-min walk test; $\mathrm{HR}=$ heart rate (beats/min); Frequency = breathing frequency (breaths/min); $\mathrm{S}_{\mathrm{aO}_{2}}=$ arterial oxygen saturation; 6MWD = 6-min walk distance; $\mathrm{AV}=$ average velocity; $\mathrm{PCl}=$ physiological cost index.

\section{Results}

A total of 168 patients were monitored at the CF outpatient unit. Ninety-six were eligible for the research. Of these, 41 individuals were excluded due to the following reasons: 15 declined the invitation, 12 had pulmonary exacerbations, 10 missed appointments, and 4 were receiving oxygen therapy. Therefore, 240 individuals were included in the total sample, 55 subjects in the CF group and 185 healthy individuals in the control group (see Fig. 2).

Table 1 presents the general characteristics of the CF group in relation to sex, BMI, pancreatic insufficiency, modified Shwachman score, gene mutation, and lung function ( $\mathrm{FEV}_{1}$ according to the predicted value). There was no significant difference between the CF group and the control group regarding weight $(37.32 \pm 15.47 \mathrm{vs} 41.61 \pm 18.04 \mathrm{~kg}$, $P=.09)$, height $(1.42 \pm 0.19$ vs $1.45 \pm 0.17 \mathrm{~m}, P=.36)$,
Table 1. General Characteristics of the Subjects With Cystic Fibrosis

\begin{tabular}{lc}
\hline \multicolumn{1}{c}{ Characteristics } & $n(\%)$ \\
\hline Sex & \\
$\quad$ Female & $33(60.0)$ \\
Male & $22(40.0)$ \\
BMI category & \\
$\quad$ Underweight & $14(25.5)$ \\
$\quad$ Normal or Healthy Weight & $35(63.6)$ \\
Overweight & $5(9.1)$ \\
Obese & $1(1.8)$ \\
Pancreatic insufficiency & \\
Yes & $44(80.0)$ \\
No & $11(20.0)$ \\
Shwachman severity score (20-100) & \\
Excellent (86-100) & $4(7.3)$ \\
Good (71-85) & $29(52.7)$ \\
Average (56-70) & $14(25.5)$ \\
Moderate (40-55) & $4(7.3)$ \\
Gene mutation & \\
$\Delta$ F508 homozygous & $17(30.9)$ \\
$\Delta$ F508 heterozygous & $27(49.1)$ \\
Unidentified & $11(20.0)$ \\
FEV,$\%$ predicted & \\
$>80$ & $19(34.5)$ \\
$60-80$ & $19(34.5)$ \\
$40-59$ & $8(14.5)$ \\
$<40$ & $2(3.6)$ \\
\hline BMI = body mass index, categories according to the Centers for Disease Control and \\
Prevention. \\
\hline
\end{tabular}

BMI (17.36 \pm 3.13 vs $\left.18.64 \pm 3.95 \mathrm{~kg} / \mathrm{m}^{2}, P=.057\right)$, and age (12.22 \pm 4.27 vs $11.25 \pm 4.30 \mathrm{y}, P=.09)$, respectively.

Regarding performance during the 6MWT, the average values of work, physiological cost index, average velocity, and 6MWD were significantly lower in the CF group compared with the control group, as follows: work: $21,690.58 \pm 10,427.77$ versus $26,057.51 \pm 11,228.49 \mathrm{~m} \times$ $\mathrm{kg}(P=.007)$; physiological cost index: $0.31 \pm 0.19$ versus $0.37 \pm 0.17$ heart rate $/ \mathrm{m} / \mathrm{min}(P=.01)$; average velocity: $94.71 \pm 12.89$ vs $104.55 \pm 9.13 \mathrm{~m} / \mathrm{min}(P<.001)$; and 6MWD: $568.02 \pm 76.31$ versus $627.54 \pm 54.81 \mathrm{~m}$ $(P<.001)$ (Table 2). The CF group walked less than predicted, whereas the control group walked a suitable distance $(568.0 \pm 76.3$ vs $624.0 \pm 72.2 \mathrm{~m}$ in the CF group with $P<.001$, and $627.5 \pm 54.8$ vs $616.1 \pm 58.3 \mathrm{~m}$ in the control group with $P=.19$ ).

Table 3 shows that 6MWD, work, and average velocity during the 6MWT were higher in subgroups of subjects with less severe disease (excellent and good), compared with the groups of subjects with more severe disease (average and moderate) according to the modified Shwachman scoring system $(P=.008, P=.01$, and $P=.007$, respectively). There was no significant difference between 
Table 2. Distribution of the Values of Work, Physiological Cost Index, Average Velocity, and 6MWD

\begin{tabular}{|c|c|c|}
\hline & Mean \pm SD & $P^{*}$ \\
\hline Work & & .007 \\
\hline $\mathrm{CF}(n=55)$ & $21,690.58 \pm 10,427.77$ & \\
\hline Control $(n=185)$ & $26,057.51 \pm 11,228.49$ & \\
\hline PCI & & .01 \\
\hline $\mathrm{CF}(n=55)$ & $0.31 \pm 0.19$ & \\
\hline Control $(n=185)$ & $0.37 \pm 0.17$ & \\
\hline AV & & $<.001$ \\
\hline $\mathrm{CF}(n=55)$ & $94.71 \pm 12.89$ & \\
\hline Control $(n=185)$ & $104.55 \pm 9.13$ & \\
\hline 6MWD, m & & $<.001$ \\
\hline $\mathrm{CF}(n=55)$ & $568.02 \pm 76.31$ & \\
\hline Control $(n=185)$ & $627.54 \pm 54.81$ & \\
\hline $\begin{array}{l}\mathrm{PCI}=\text { physiological cost in } \\
\mathrm{AV}=\text { average velocity }(\mathrm{m} / \mathrm{r} \\
6 \mathrm{MWD}=6 \text {-min walk distar } \\
\mathrm{CF}=\text { cystic fibrosis } \\
* P \text { using nonparametric }\end{array}$ & $\mathrm{te} / \mathrm{m} / \mathrm{min})$ & \\
\hline
\end{tabular}

Table 3. Distribution of 6MWD, Work, PCI, and AV, According to the Disease Severity Determined by Shwachman Score in the CF Group

\begin{tabular}{|c|c|c|c|}
\hline Shwachman Score* & $n$ & Mean \pm SD & $P \dagger$ \\
\hline \multicolumn{3}{|l|}{ 6MWD } & .008 \\
\hline Excellent & 4 & $704.10 \pm 90.12$ & \\
\hline Good & 29 & $563.81 \pm 60.02$ & \\
\hline Average & 14 & $554.24 \pm 79.32$ & \\
\hline Moderate & 4 & $496.00 \pm 45.69$ & \\
\hline \multicolumn{3}{|l|}{ Work, $\mathrm{m} \times \mathrm{kg}$} & .01 \\
\hline Excellent & 4 & $39,005.40 \pm 10,204 \cdot 14$ & \\
\hline Good & 29 & $21,147.09 \pm 8,489.83$ & \\
\hline Average & 14 & $18,295.94 \pm 9,063.18$ & \\
\hline Moderate & 4 & $13,781.17 \pm 5,474.94$ & \\
\hline \multicolumn{3}{|l|}{ PCI } & .95 \\
\hline Excellent & 4 & $0.33 \pm 0.10$ & \\
\hline Good & 29 & $0.30 \pm 0.17$ & \\
\hline Average & 14 & $0.32 \pm 0.25$ & \\
\hline Moderate & 4 & $0.37 \pm 0.28$ & \\
\hline \multicolumn{3}{|l|}{ AV } & .007 \\
\hline Excellent & 4 & $117.35 \pm 15.02$ & \\
\hline Good & 29 & $94.45 \pm 9.42$ & \\
\hline Average & 14 & $91.66 \pm 14.43$ & \\
\hline Moderate & 4 & $82.28 \pm 8.40$ & \\
\hline \multicolumn{4}{|c|}{$\overline{\mathrm{PCI}}=$ physiological cost index (heart rate $/ \mathrm{m} / \mathrm{min}$ ) } \\
\hline \multirow{2}{*}{\multicolumn{4}{|c|}{$\begin{array}{l}\mathrm{AV}=\text { average velocity }(\mathrm{m} / \mathrm{min}) \\
6 \mathrm{MWD}=6 \text {-min walk distance }\end{array}$}} \\
\hline & & & \\
\hline \multicolumn{4}{|l|}{$\mathrm{SD}=$ standard deviation } \\
\hline \multicolumn{4}{|c|}{$\begin{array}{l}* \text { Modified Shwachman score }(\text { moderate }=40-55 ; \text { average }=56-70 ; \text { good }=71-85 \text {; } \\
\text { excellent }=86-100)\end{array}$} \\
\hline$\dagger P$ using the nonparametr & & & \\
\hline
\end{tabular}

mean levels of physiological cost index in the different severity subclasses $(P=.95)$. In the analysis of spirometric data of $\mathrm{FEV}_{1}$, there was no difference between the mean values of $6 \mathrm{MWD}$, work, physiological cost index,
Table 4. Distribution of CD, Work, PCI, and AV, According to Percentage of Predicted $\mathrm{FEV}_{1}$ in the CF Group

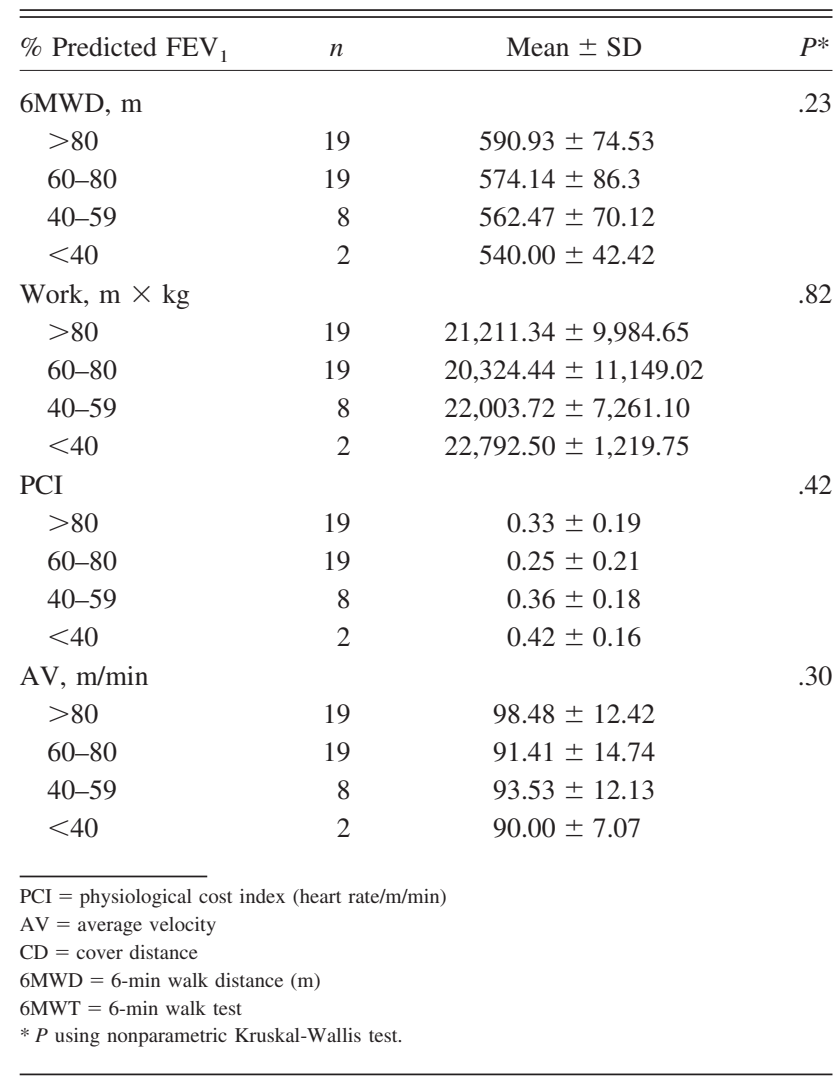

and average velocity, considering the disease severity by predicted $\mathrm{FEV}_{1}$ of the CF group (Table 4).

BMI, modified Shwachman score, and $\mathrm{FEV}_{1}$ of the CF group did not show any correlation with physiological cost index $(\mathrm{r}=0.20, P=.14 ; \mathrm{r}=0.06, P=.60$; and $\mathrm{r}=0.14$, $P=.32$, respectively), but all outcomes were correlated with work $(\mathrm{r}=0.82, P<.001 ; \mathrm{r}=0.30, P=.02$; and $\mathrm{r}=0.83, P<.001) .6 \mathrm{MWD}$ was not correlated with BMI ( $\mathrm{r}=0.20, P=.14)$ but with modified Shwachman score $(\mathrm{r}=0.28, P=.040)$ and with $\mathrm{FEV}_{1}(\mathrm{r}=0.43, P<.001)$. Average velocity was correlated with modified Shwachman score $(\mathrm{r}=0.31, P=.02)$ and with $\mathrm{FEV}_{1}(\mathrm{r}=.43$, $P<.001)$ but not with BMI $(\mathrm{r}=.20, P=.14)$. In the control group, only BMI was correlated with work $(\mathrm{r}=0.866, P<.001)$.

\section{Discussion}

The identification of alternative variables to assess the functional capacity of patients with chronic diseases, especially cystic fibrosis, is a topic of great clinical relevance. Decreased ability to perform physical exercises is one of the major characteristics of cardiopulmonary diseases such as CF. ${ }^{24}$ Some patients experience exercise 
limitations due to changes in pulmonary function, peripheral muscles, nutritional status, and the ability of the cardiorespiratory system to meet the metabolic demand associated with exercise. ${ }^{25,26}$ Chronic pulmonary infection and poor adherence to treatment play an important role in the progression of exercise intolerance in $\mathrm{CF}^{4,27}$

The physiological effects of fibrocystic diseases are similar to those of cardiovascular deconditioning, namely reduced cardiovascular function, loss of muscle mass, and decreased muscular strength. Furthermore, patients with $\mathrm{CF}$ are often physically inactive due to chronic pulmonary conditions, which considerably increase health risks. ${ }^{28}$ Some studies have reported an association between aerobic capacity and the clinical status of children with $\mathrm{CF}$ and considered such association as a predictor of survival. ${ }^{29,30}$

Assessing fitness and exercise tolerance in CF may be useful to measure the impact of the disease, especially when performed on a routine basis. It can be used to identify individual functional limitations as well as to portray the impact of the disease on daily activities and quality of life. Exercise tolerance testing can also add prognostic information about the disease and help in prescribing safe exercise. Finally, it is considered as an outcome measure to assess response to therapies. ${ }^{31}$

In this context, constant monitoring of exercise capacity in this population is necessary, as well as the investigation of several factors that contribute to exercise limitation. In this way, appropriate interventions can be conducted to avoid the decline of functional capacity and the consequences of disease evolution. ${ }^{31}$

The 6MWT is a simple method to estimate the submaximal exercise capacity. It is well tolerated by patients with chronic diseases and has significant correlation with maximum oxygen uptake, for providing important data to monitor CF evolution as well as for its role as an indicator of the effect of new therapies and a guide to disease management. ${ }^{32,33}$

The 6MWD presented as an important standard measure to assess submaximal exercise tolerance. The use of additional parameters can also help professionals regarding the analysis of functional capacity of patients with CF.

Therefore, in addition to 6MWD, this study assessed work, average velocity, and physiological cost index using the 6MWT variables. This study also identified functional impairment among subjects with CF more accurately, supporting scientific assertions of inactivity, deconditioning, and low exercise tolerance of these patients. ${ }^{2,9,28,31}$ These indexes bring additional information to assess functional exercise capacity, especially when the conventional measurement of submaximal exercise capacity (measured by 6MWD) may not be sufficient.

The search for alternative indexes has proved valid, yet the 6MWD has been considered inconsistent, despite its reliability and validity for the investigation of functional capacity, when compared with other measures to determine functional capacity, morbidity, and mortality. ${ }^{10}$ Some factors that interfere with 6MWD and ambulation may explain this deficiency, such as the influence of anthropometric factors (height and weight), sex, age, lung function, ethnicity, and length of the lower limbs. ${ }^{10}$ This factors promote major influence in the pediatric population, became the interpretation more difficult.

Moreover, 6MWD is often monitored to assess clinical changes resulting from treatment. Its analysis is based on a minimum difference, where a minimum distance gain indicates positive therapeutic effect. In COPD, a mean change of 25-35 m has been reported as a clinically important change. ${ }^{34,35}$ In $\mathrm{CF}$, this framework is still nonexistent. Therefore, studies that use the 6MWT as an evaluation tool will consider only the increase or decrease of 6MWD, without trying to determine its clinical importance.

In this context, some studies also used age-predicted 6MWD values as an alternative form of measurement. However, these values and reference equations were obtained from studies with healthy children and adolescents. $^{21,36-38}$ Clearly, applying values of healthy populations for the analysis of chronically ill subjects brings inconsistency to the results. Furthermore, there are methodological differences in the implementation of the 6MWT between surveys and anthropometric variations within the study samples. This type of comparison was applied in this study. As expected, the CF group showed significantly lower 6MWD values than predicted: a gap of about $80 \mathrm{~m}$. This did not happen within the control group.

These gaps are responsible for confusing or misleading the interpretation of $6 \mathrm{MWD}$ values in children with $\mathrm{CF}$, because there are no reference values to determine the clinical importance of these results, which led to the investigation of alternative indexes, as reported in this study. The indexes were adapted to generate new exercise tolerance measurement variables and to improve the understanding and investigation of this test among patients with CF. ${ }^{10,15,31}$

In this study, work performed during walking was lower in the CF group compared with the control group. This variable was able to detect differences between subjects with more severe disease and subjects with less severe disease: The greater the severity of the disease, the lower the work rate. Additionally, work is better correlated with $\mathrm{FEV}_{1}$, modified Shwachman score, and BMI.

The work calculation takes into account the mass of the body and energy required to move that body through space. The close relationship between work and nutritional status was supported by a correlation between work and BMI in both groups. The weight loss observed in patients with $\mathrm{CF}$ directly affects the necessary work performed during walking and therefore interferes with 6MWD and work values. 
The significant correlation between $\mathrm{FEV}_{1}$ and work may reflect the ventilatory limitation to exercise. The leg fatigue can also be associated with exercise limitation related to work values. ${ }^{10}$

In a study with 33 subjects with COPD, work was calculated using the 6MWT and showed good correlation with changes in the levels of oxygen saturation levels, carbon monoxide, anaerobic threshold, and maximum oxygen uptake, compared with 6MWD results. The authors suggest the use of this variable to replace 6MWD if the maximal cardiopulmonary exercise test cannot be applied. ${ }^{11}$ Also in COPD, another study showed significant correlation between work volume during the 6MWT and maximal work performed during an incremental cyclo-ergometric test. ${ }^{39}$ The 6MWT work results correlated with maximum oxygen uptake in $\mathrm{CF}$ subjects but not with the 6MWD. Average velocity results showed lower speed during the 6MWT in the CF group, compared with the control group, probably influenced by disease severity. Walking speed is a convenient variable to measure overall gait and functional mobility. Slow walking speed is related to some factors, such as decreased muscle strength and power, loss of independence, morbidity, and mortality in patients with chronic diseases.

In this study, average velocity values were correlated with modified Shwachman score and $\mathrm{FEV}_{1}$. It seems to be a good parameter that could represent overall disease conditions, not only due to respiratory limitations. In patients with COPD, gait speed is associated with poor exercise capacity and related to physical activity level, cognitive function, depression, and quality of life. It is considered a powerful and informative tool to improve clinical care in this population..$^{40}$

The physiological cost index was first described and presented as an objective measurement by MacGregor ${ }^{15}$ in 1979. It provides an estimate of energy expenditure, based on a linear relationship between heart rate and oxygen uptake during submaximal exercise. Based on the definition and the above-mentioned results, it can be suggested that the $\mathrm{CF}$ group required higher oxygen uptake during submaximal exercise (6MWT), compared with the control group.

Considering that heart rate decreases and the walking speed increases with age, the physiological cost index assessment showed well-balanced and proportional results at all ages. This fact can be considered a positive element for the inclusion of physiological cost index assessments in studies using the 6MWT, since 6MWD is directly influenced by age and anthropometric parameters. ${ }^{13}$ They are considered as potential confounding elements, which may cause disturbance or mislead interpretation of test results, underestimate physical capacity in chronic diseases, and mask the effects of interventions. Nevertheless, in our study, due to large variations in age, we did not observe correlations between physiological cost index and BMI, $\mathrm{FEV}_{1}$, and modified Shwachman score. In this context, the 6MWT and respective variables comprise a better view of functional capacity and are possible to monitor among patients with CF. ${ }^{41}$

Lower values of cover distance (CD), work, and average velocity could be observed in cases of more severe disease. The modified Shwachman score used to assess CF severity included physical conditions, nutritional status, lung disease, and general aspects of the disease. The determinants of exercise limitations involved pulmonary conditions, cardiac and nutritional factors, peripheral skeletal muscle function, physical activity levels, anthropometric changes, medications used, degree of inflammation, cystic fibrosis transmembrane regulator mutation, and psychological and social aspects. ${ }^{42}$ The association between indexes and disease severity shows that these indexes can help estimate overall aspects of CF. Others factors may influence exercise tolerance, including weight (which reflects nutritional status by work), muscle mass related to velocity, and cardiopulmonary behavior represented by physiological cost index. These factors can be approached by estimated indexes from the 6MWT. They also provide better understanding of the limiting factors that determine exercise capacity.

There was no difference between the indexes and pulmonary function represented by $\mathrm{FEV}_{1}$. The lack of association can be explained by the presence of CF subjects with $\mathrm{FEV}_{1} \geq 0.6$. In contrast, approximately $18 \%(n=10)$ had values $<0.6$. Studies showed a correlation between pulmonary function and variables of cardiopulmonary tests in subjects with severe lung disease classified by $\mathrm{FEV}_{1}<0.5$. The exercise response did not depend on $\mathrm{FEV}_{1}$ in mild-to-moderate lung disease. ${ }^{43,44}$ Pulmonary function explains only about one third of the variability in exercise capacity. ${ }^{43}$ No improvement was found in lung function and maximal exercise capacity of children and adolescents with CF after a 3-month aerobic exercise program based on verbal and written guidelines. However, a positive impact on regular physical exercise practice could be observed. ${ }^{45}$ Furthermore, the application of the quality of life questionnaire could be considered as an important factor to provide a view of the general aspects of the disease.

Further studies should be conducted to provide a better understanding of the interpretation of these variables and of the analysis of functional capacity in patients with $\mathrm{CF}$. Notably, the 6MWT is an easy-to-implement test. Additional methods of interpretation should be investigated to obtain additional information, since maximal cardiopulmonary exercise tests, although they are considered the accepted standard test, are more expensive, difficult to implement, and poorly tolerated, especially by patients with CF. ${ }^{46}$

This study had some limitations. It was not possible to observe differences between any of the alternative indexes 


\section{Alternative IndeXes to the 6MWT in Subjects With CF}

and the pulmonary function in the CF group, here characterized by the spirometry parameter of $\mathrm{FEV}_{1}$. We suggest that other spirometry variables, such as forced expiratory flow between 25 and $75 \%$ of FVC $\left(\mathrm{FEF}_{25-75 \%}\right)$, may be more appropriate to assess such a relationship. This can be explained by the fact that $\mathrm{FEF}_{25-75 \%}$ detects the decline in lung function earlier than $\mathrm{FEV}_{1}$, because $\mathrm{FEF}_{25-75 \%}$ represents the peripheral airways, a lung region that is mainly affected in CF.

Another limitation of this study was the broad age range of subjects. The behavior analysis of these indexes, considering age-related anatomical and physiological changes, could produce even more sensitive results. Also, the number of subjects in various subgroups (lung function and disease severity) may have been too small for sufficient statistical analysis.

\section{Conclusions}

The estimated indexes of functional capacity from the 6MWT, including work, physiological cost index, and average velocity, proved to be useful in the analysis of exercise tolerance in subjects with $\mathrm{CF}$, as well as 6MWD during the test. These indexes could provide additional parameters to evaluate functional capacity in patients with $\mathrm{CF}$ and contribute to a better understanding of limiting factors of exercise response.

\section{REFERENCES}

1. Mogayzel PJ Jr, Flume PA. Update in Cystic Fibrosis 2009. Am J Respir Crit Care Med 2010;181(6):539-544.

2. Kuca K, Klimova B, Novotny M, Maresova P. Cystic fibrosis revisited: a review study. Med Chem 2016. [Epub ahead of print].

3. Narang I, Pike S, Rosenthal M, Balfour-Lynn IM, Bush A. Threeminute step test to assess exercise capacity in children with cystic fibrosis with mild lung disease. Pediatr Pulmonol 2003;35(2):108113.

4. Cox NS, Alison JA, Button BM, Wilson JW, Morton JM, Holland AE. Physical activity participation by adults with cystic fibrosis: an observational study. Respirology 2016;21(3):511-518.

5. Gruet M, Brisswalter J, Mely L, Vallier JM. Use of the peak heart rate reached during six-minute walk test to predict individualized training intensity in patients with cystic fibrosis: validity and reliability. Arch Phys Med Rehabil 2010;91(4):602-607.

6. Noonan V, Dean E. Submaximal exercise testing: clinical application and interpretation. Phys Ther 2000;80(8):782-807.

7. Arikan H, Yatar İ, Calik-Kutukcu E, Aribas Z, Saglam M, VardarYagil N, et al. A comparison of respiratory and peripheral muscle strength, functional exercise capacity, activities of daily living and physical fitness in patients with cystic fibrosis and healthy subjects. Res Dev Disabil 2015;45(46):147-156.

8. ATS Committee on Proficiency Standards for Clinical Pulmonary Function Laboratories. ATS statement: guidelines for the six-minute walk test. Am J Respir Crit Care Med 2002;166(1):111-117.

9. Gulmans VA, van Veldhoven NH, de Meer K, Helders PJ. The six-minute walking test in children with cystic fibrosis: reliability and validity. Pediatr Pulmonol 1996;22(2):85-89.
10. Carter R, Holiday DB, Nwasuruba C, Stocks J, Grothues C, Tiep B. 6-minute walk work for assessment of functional capacity in patients with COPD. Chest 2003;123(5):1408-1415.

11. Chuang ML, Lin IF, Wasserman K. The body weight-walking distance product as related to lung function, anaerobic threshold and peak $\mathrm{VO}_{2}$ in COPD patients. Respir Med 2001;95(7):618-626.

12. Graham JE, Ostir GV, Kuo YF, Fisher SR, Ottenbacher KJ. Relationship between test methodology and mean velocity in timed walk tests: a review. Arch Phys Med Rehabil 2008;89(5):865-872.

13. Bratteby Tollerz LU, Olsson RM, Forslund AH, Norrlin SE. Reliability of energy cost calculations in children with cerebral palsy, cystic fibrosis and health controls. Acta Paediatr 2011;100(12):16161620.

14. Butler P, Engelbrecht M, Major RE, Tait JH, Stallard J, Patrick JH. Physiological cost index of walking for normal children and its use as an indicator of physical handicap. Dev Med Child Neurol 1984; 26(5):607-612.

15. MacGregor J. The objective measurement of physical performance with long-term ambulatory physiological surveillance equipment. In: Stott FD, Raftery EB, Goulding L, editors. Proceedings of the Third International Symposium on Ambulatory Monitoring. London: Academic Press; 1979:29-39.

16. Kanga J, Kuhn R, Craigmyle L, Haverstock D, Church D. Cystic fibrosis clinical score: a new scoring system to evaluate acute pulmonary exacerbation. Clin Ther 1999;21(8):1343-1356.

17. Hafen GM, Ranganathan SC, Robertson CF, Robinson PJ. Clinical scoring system in cystic fibrosis. Pediatr Pulmonol 2006;41(7):602617.

18. Shwachman H, Kulczycki LL. Long term study of one hundred five patients with cystic fibrosis. Am J Dis Child 1958;96(18):6-15.

19. Doeurshuk CF, Matthews LW, Tucker AS, Nudelman H, Eddy G, Wise M, Spector S. A 5 year clinical evaluation of a therapeutic program for patients with cystic fibrosis. J Pediatr 1964;65(5):677693.

20. Santos CIS, Ribeiro JD, Ribeiro AF, Hessel G. Critical analysis of scoring systems used in the assessment of cystic fibrosis severity: state of the art. J Bras Pneumol 2004;30(3):286-298.

21. Priesnitz CV, Rodrigues GH, Stumpf Cda S, Viapiana G, Cabral CP, Stein RT, et al. Reference values for the 6-min walk test in healthy children aged 6-12 years. Pediatr Pulmonol 2009;44(12):1174-1179.

22. Sociedade Brasileira de Pneumologia e Tisiologia. Diretrizes para testes de função pulmonar. J Pneumol 2002;28(3):S1-S238.

23. Miller MR, Hankinson J, Brusasco V, Burgos F, Casaburi R, Coates A, et al. ATS/ERS statement: standardisation of lung function testing. Eur Respir J 2005;26(2):319-338.

24. Rasekaba T, Lee AL, Naughton MT, Williams TJ, Holland AE. The six-minute walk test: a useful metric for the cardiopulmonary patient. Intern Med J 2009;39(8):495-501.

25. Lands LC, Heigenhauser GJ, Jones NL. Analysis of factors limiting maximal exercise performance in cystic fibrosis. Clin Sci 1992;83(4): 391-397.

26. Coates AL, Boyce P, Muller D, Mearns M, Godfrey S. The role of nutritional status, airway obstruction, hypoxia, and abnormalities in serum lipid composition in limiting exercise tolerance in children with cystic fibrosis. Acta Paediatr Scand 1980;69(3):353-358.

27. Prasad SA, Cerny FJ. Factors that influence adherence to exercise and their effectiveness: application to cystic fibrosis. Pediatr Pulmonol 2002;34(1):66-72.

28. Wilkes DL, Schneiderman JE, Nguyen T, Heale L, Moola F, Ratjen F, et al. Exercise and physical activity in children with cystic fibrosis. Paediatr Respir Rev 2009;10(3):105-109.

29. Nixon PA, Joswiak ML, Fricker FJ. A six-minute walk test for assessing exercise tolerance in severely ill children. J Pediatr 1996; 129(3):362-366. 


\section{Alternative IndeXes to the 6MWT in Subjects With CF}

30. Boucher GP, Lands LC, Hay JA, Hornby L. Activity levels and the relationship to lung function and nutritional status in children with cystic fibrosis. Am J Phys Med Rehabil 1997;76(4):311-315.

31. Rogers D, Prasad SA, Doull J. Exercise testing in children with cystic fibrosis. J R Soc Med 2003;96(43):23-29.

32. Morales-Blanhir JE, Palafox Vidal CD, Rosas Romero Mde J, García Castro MM, Londoño Villegas A, Zamboni M. Six-minute walk test: a valuable tool for assessing pulmonary impairment. J Bras Pneumol 2011;37(1):110-117.

33. Cahalin L, Pappagianopoulos P, Prevost S, Wain J, Ginns L. The relationship of the 6-min walk test to maximal oxygen consumption in transplant patients with end-stage lung disease. Chest 1995;108(2):452-459.

34. Puhan MA, Mador MJ, Held U, Goldstein R, Guyatt GH, Schümann HJ. Interpretation of treatment changes in 6-minute walk distance in patients with COPD. Eur Respir J 2008;32(3):637-643.

35. Holland AE, Hill CJ, Rasekaba T, Lee A, Naughton MT, McDonald CF. Updating the minimal importance difference for six-minute walk distance in patients with chronic obstructive pulmonary disease. Arch Phys Med Rehabil 2010;91(2):221-225.

36. Geiger R, Strasak A, Treml B, Gasser K, Kleinsasser A, Fischer V, et al. Six-minute walk test in children and adolescents. J Pediatr 2007;150(4):395-399.

37. Lammers AE, Hislop AA, Flynn Y, Haworth SG. The 6-minute walk test: normal values for children of 4-11 years of age. Arch Dis Child 2008;93(6):464-468.

38. Li AM, Yin J, Au JT, So HK, Tsang T, Wong E, et al. Standard reference for the 6-minute walk test in healthy children aged 7 to 16 years. Am J Respir Crit Care Med 2007;176(2):174-180.
39. Hill K, Jenkins SC, Cecins N, Philippe DL, Hillman DR, Eastwood PR. Estimating maximum work rate during incremental cycle ergometry testing from six-minute walk distance in patients with chronic obstructive pulmonary disease. Arch Phys Med Rehabil 2008;89(9):1782-1787.

40. Karpman C, DePew ZS, LeBrasseur NK, Novotny PJ, Benzo RP. Determinants of gait speed in COPD. Chest 2014;146(1):104-110.

41. Orenstein DM, Franklin BA, Doershuk CF, Hellerstein HK, Germann KJ, Horowitz JG, Stern RC. Exercise conditioning and cardiopulmonary fitness in cystic fibrosis. The effects of a three months supervised running program. Chest 1981;80(4):392-398.

42. Selvadurai HC, McKay KO, Blimkie CJ, Cooper PJ, Mellis CM, Van Asperen PP. The relationship between genotype and exercise tolerance in children with cystic fibrosis. Am J Respir Crit Care Med 2002;165(6):762-765.

43. Almajed A, Lands LC. The evolution of exercise capacity and its limiting factors in cystic fibrosis. Paediatr Respir Rev 2012;13(4): 195-199.

44. Pastré J, Prévotat A, Tardif C, Langlois C, Duhamel A, Wallaert B. Determinants of exercise capacity in cystic fibrosis patients with mild-to-moderate lung disease. BMC Pulm Med 2014;14:74.

45. Hommerding PX, Baptista RR, Makarewicz GT, Schindel CS, Donadio MV, Pinto LA, Marostica PJ. Effects of an educational intervention of physical activity for children and adolescents with cystic fibrosis: a randomized controlled trial. Respir Care 2015;60(1):81-87.

46. Hebestreit H, Arets HG, Aurora P, Boas S, Cerny F, Hulzebos EH, et al. Statement on exercise testing in cystic fibrosis. Respiration 2015;90(4):332-351. 